\title{
Application of a plug-flow column model to a biologically activated carbon pilot plant
}

\author{
Jung A Rhim ${ }^{\dagger}$ and Jeong Hyo Yoon* \\ School. of Environmental Science, Catholic University of Pusan, Pusan 609-757, Korea \\ *Department of Chemistry, Pusan National University, Pusan 609-735, Korea \\ (Received 28 February 2005 - accepted 5 January 2007)
}

\begin{abstract}
The plug flow stationary solid phase column model provides a exact description of adsorption dynamics, considers external mass transfer, internal diffusion transport, intra-biofilm diffusion, and above all, spatial and temporal variation of biofilm thickness in adsorbers. The purpose of this paper is to evaluate the applicability of the plug-flow stationary solid phase column model in the biological activated carbon pilot plant by investigating the breakthrough behavior of dissolved organic carbon. The breakthrough profile of dissolved organic carbon measured under the bed volume of 10,000 was 0.425 . The predicted breakthrough curves by the plug flow stationary solid phase column model maintained a certain value of 0.45 according to the bed volume. Therefore, the plug-flow stationary solid phase column model provided a good accuracy for prediction of breakthrough profiles in the biological activated carbon pilot plant.
\end{abstract}

Key words: Biological Activated Carbon, Plug-flow Stationary Solid Phase Column Model, Dissolved Organic Carbon

\section{INTRODUCTION}

Biological activated carbon (BAC) is defined as a simultaneous combination process in which granular activated carbon (GAC) adsorption of dissolved organic materials is coupled with aerobic biological oxidation of organic materials [1]. The purpose of this paper is to evaluate the applicability of the plug-flow stationary solid phase column model in the BAC Pilot Plant by investigating the concentrations of dissolved organic carbon (DOC) through adsorption and biodegradation.

Biodegradation and adsorption are unsteady-state processes taking place during the service life of carbon bed. Major factors influencing the rate of each process are transport of materials in the liquid phase, microbial growth kinetics, intra-particle transport kinetics, and adsorption onto the solid phase. Extensive studies have been conducted to develop mathematical models which take into consideration the above-mentioned factors for fixed, expended or fluidized activated carbon beds [2-6].

Jennings investigated the removal of biodegradable compounds by attached film growth and presented a phenomenological analysis in terms of simultaneous diffusion and chemical reaction of the species across the biofilm [3]. His model essentially employed a lumped-parameter approach, representing the organic species as total organic carbon.

The mathematical conceptualization of Jennings was extended by Peel and Benedek whose predictive model assumed plug flow conditions, with the carbon particle held in stationary positions in the adsorber column [4]. An additional assumption was that film thickness was considered as a fixed, externally defined parameter. This approximation worked reasonably well for prediction of longterm performance of their system, although higher removals were predicted at the initial stages of column operation, as demonstrated

To whom correspondence should be addressed.

E-mail: jarhim@korea.com by the investigators. This might be attributed to the fact that at the commencement of the operation cycle the biofilm is very thin, and as time progresses the film thickness increases. It was necessary to develop a model that considered the spatial and temporal variations of biofilm thickness in adsorbers.

The advantage of the model developed in this paper incorporates a number of features to obviate the limitations of previous models for organic carbon removal. This model provides an exact description of adsorption dynamics, considers external mass transfer, internal diffusion transport, intra-biofilm diffusion, and above all, spatial and temporal variation of biofilm thickness in adsorbers. Also, this model employs different initial and boundary conditions. Furthermore, this model is applicable to a plug flow column as well as completely mixed fluidized bed designs, and is intended to be applied to a water and wastewater with radically different total organic carbon levels, and components manifesting varying adsorption or biodegradation characteristics.

\section{EXPERIMENTAL METHODS}

The ozone generator is a silent electrical discharger that has a water cooling system at the outside of the discharge tube and filter, which is a moisture filter and is used to remove nitric acid caused by humidity. The ozone contactor is made of acrylic and its height and diameter are $4,000 \mathrm{~mm}$ and $300 \mathrm{~mm}$, respectively. The ozone contactor is a bubble column that has a continuous liquid phase and dispersed gas phase where the factors of reactor performance are the size of the bubble, gas holdup, and flow characteristics [7-9]. The gaseous ozone concentration is $1 \mathrm{mg} \mathrm{O}_{3} / \mathrm{L}$, ozone contact time is 10 minutes, ozonated air flow rate is $3.3 \mathrm{~m}^{3} /$ hour. The optimum conditions to increase the biodegradable dissolved organic carbon (BDOC) were assumed to be $2-3 \mathrm{mg} \mathrm{O}_{3} / \mathrm{L}$ of ozone dose in the ozone contactor [10-12].

The BAC Pilot Plant used in the continuous experiment is shown in Fig. 1. The BAC reactor is made of acrylic and its height and 


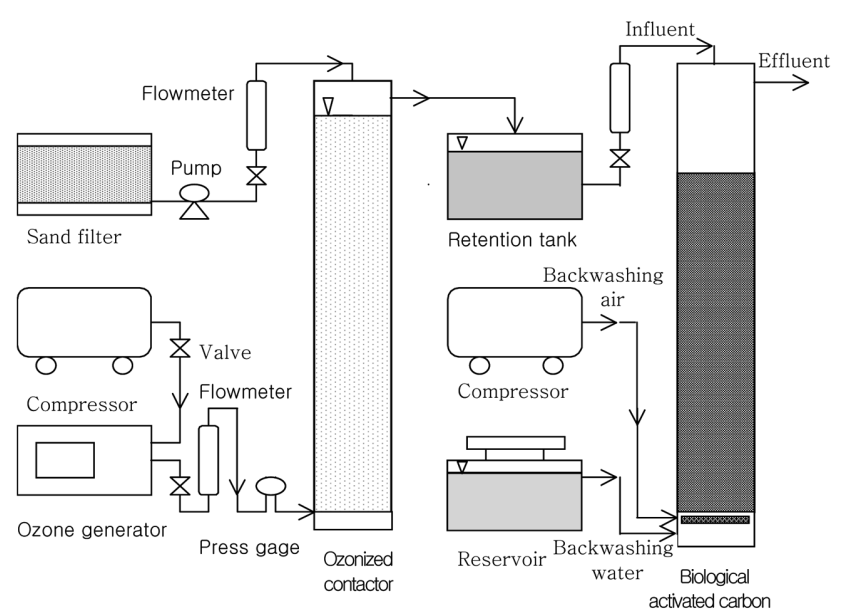

Fig. 1. Schematic diagram of the experimental apparatus in a BAC pilot plant.

diameter are $6,000 \mathrm{~mm}$ and $400 \mathrm{~mm}$, respectively. The height of the packed $\mathrm{GAC}$ is $3,000 \mathrm{~mm}$ and its volume is $375 \mathrm{~L}$. The empty bed contact time (EBCT) in the BAC Pilot Plant is from 5 to 15 minutes. The flow-rate for the influent in the BAC Pilot Plant is 25 $\mathrm{L} / \mathrm{min}$ and the linear velocity is $12 \mathrm{~m} / \mathrm{hr}$.

The BDOC concentrations were measured at $20^{\circ} \mathrm{C}$ by using mixed indigenous fixed bacteria. The BDOC concentrations were expressed as the difference between the initial DOC and the lowest DOC value measured during the incubation period [10,13-15]. Water samples were collected in organic carbon-free brown glass bottles. The bottles were carefully washed and treated at $550{ }^{\circ} \mathrm{C}$ for three hours. The DOC concentrations are analyzed on a DORHMAN which provides a $3 \%$ error on small DOC concentrations $(<3 \mathrm{mg} / \mathrm{L})$.

\section{PLUG-FLOW STATIONARY SOLID PHASE COLUMN MODEL DEVELOPMENTS}

\section{Liquid Phase Material Balance}

The material balance of the dissolved substrates to be removed for any differential segment of the bed is represented by the equation $[12,16]$.

$$
\begin{aligned}
\frac{\partial \mathrm{C}(\mathrm{x}, \mathrm{t})}{\partial \mathrm{x}}= & \mathrm{D}_{d} \frac{\partial^{2} \mathrm{C}(\mathrm{x}, \mathrm{t})}{\partial \mathrm{x}^{2}}-\mathrm{v}_{x} \frac{\partial \mathrm{C}(\mathrm{x}, \mathrm{t})}{\partial \mathrm{x}} \\
& -\frac{3 \mathrm{k}_{f c}(1-\varepsilon)}{\varepsilon} \frac{\left(\mathrm{R}+\mathrm{L}_{f}\right)^{2}}{\mathrm{R}^{3}}\left[\mathrm{C}(\mathrm{x}, \mathrm{t})-\mathrm{C}_{f \mathrm{~s}}(\mathrm{x}, \mathrm{t})\right]
\end{aligned}
$$

whose initial and boundary conditions are

$$
\mathrm{C}(\mathrm{x}, \mathrm{t}=0)=0, \mathrm{C}(\mathrm{x}=0, \mathrm{t})=\mathrm{C}_{0},\left.\frac{\partial \mathrm{C}(\mathrm{x}, \mathrm{t})}{\partial \mathrm{x}}\right|_{x=L}=0
$$

\section{Solid Phase Material Balance in the Adsorbent}

The homogeneous surface diffusion model used for intra-particle diffusion of adsorbed substrate can be represented by

$$
\frac{\partial \mathrm{q}(\mathrm{r}, \mathrm{t})}{\partial \mathrm{t}}=\frac{\mathrm{D}_{s}}{\mathrm{r}^{2}} \frac{\partial}{\partial \mathrm{r}}\left[\mathrm{r}^{2} \frac{\partial \mathrm{q}(\mathrm{r}, \mathrm{t})}{\partial \mathrm{r}}\right]
$$

whose initial and boundary conditions are

$$
\mathrm{q}(0 \leq \mathrm{r} \leq \mathrm{R}, \mathrm{t}=0)=0, \mathrm{q}(\mathrm{r}=\mathrm{R}, \mathrm{t})=\mathrm{q}_{\mathrm{s}}(\mathrm{t}), \frac{\partial \mathrm{q}\left(\mathrm{r}=0, \mathrm{t} \geq \mathrm{t}_{0}\right)}{\partial \mathrm{r}}=0
$$

Another boundary condition can be introduced by performing mass balance on an adsorbent particle as shown below:

$$
\begin{aligned}
\frac{3}{\mathrm{R}^{3}} \frac{\partial}{\partial \mathrm{t}} \int_{0}^{R} \mathrm{q}(\mathrm{r}, \mathrm{t}) \mathrm{r}^{2} \mathrm{dr}= & \frac{\mathrm{k}_{f c} \mathrm{~A}_{p}}{\mathrm{~V}_{c} \rho_{a}}\left[\mathrm{C}(\mathrm{x}, \mathrm{t})-\mathrm{C}_{f s}(\mathrm{x}, \mathrm{t})\right] \\
& -\frac{3 \mathrm{k} \mathrm{X}_{f} \mathrm{~L}_{f}}{\mathrm{Y} \rho_{a} \mathrm{R}} \frac{\mathrm{C}_{f a v g}(\mathrm{x}, \mathrm{t})}{\mathrm{K}_{s}+\mathrm{C}_{f a v g}(\mathrm{x}, \mathrm{t})}
\end{aligned}
$$

\section{Diffusion and Reaction in the Biofilm}

Assuming that substrate concentration within the biofilm changes only in the $\mathrm{z}$ direction, normal to the surface of the biofilm is at pseudo steady-state, the following relation can be written:

$$
\mathrm{D}_{f} \frac{\partial^{2} \mathrm{C}_{f}(\mathrm{x}, \mathrm{z}, \mathrm{t})}{\partial \mathrm{z}^{2}}=\frac{\mathrm{kX}_{f} \mathrm{C}_{f}(\mathrm{x}, \mathrm{z}, \mathrm{t})}{\mathrm{K}_{s}+\mathrm{C}_{f}(\mathrm{x}, \mathrm{z}, \mathrm{t})}
$$

The boundary conditions corresponding to the above equation are the following:

$$
\mathrm{C}_{\mathcal{N}}(\mathrm{x}, \mathrm{z}=0, \mathrm{t})=\mathrm{C}_{s}(\mathrm{x}, \mathrm{t}), \mathrm{C}_{\mathcal{N}}(\mathrm{x}, \mathrm{Z}=\mathrm{L}, \mathrm{t})=\mathrm{C}_{\beta}(\mathrm{x}, \mathrm{t})
$$

\section{Growth of Biofilm}

If the Monod growth model is used, the variation of biofilm thickness with time can be adequately represented by

$$
\frac{\partial \mathrm{L}_{f}(\mathrm{x}, \mathrm{t})}{\partial \mathrm{t}}=\frac{\mathrm{kC}_{\text {frog }}(\mathrm{x}, \mathrm{t})}{\mathrm{K}_{s}+\mathrm{C}_{\text {favg }}(\mathrm{x}, \mathrm{t})}-\mathrm{k}_{d} \mathrm{~L}_{f}(\mathrm{x}, \mathrm{t})
$$

The initial and boundary conditions are

$$
\mathrm{L}_{\mathcal{N}}(\mathrm{x}, \mathrm{t}=0)=\mathrm{L}_{f o}, \mathrm{~L}_{\mathcal{N}}\left(\mathrm{x}, \mathrm{t}=\mathrm{t}_{\text {max }}\right)=\mathrm{L}_{\text {fmax }}
$$

\section{Adsorption Equilibrium Relationship}

The Freundlich adsorption model used to relate the equilibrium solid phase concentration to liquid phase concentration near the exterior particle surface can be written as

$$
\mathrm{q}(\mathrm{r}=\mathrm{R}, \mathrm{x}, \mathrm{t})=\mathrm{K}_{F} \mathrm{C}_{s}(\mathrm{x}, \mathrm{t})^{n}
$$

Eqs. (1) through (6) can be non-dimensionalized by defining the following dimensionless variables:

$$
\begin{aligned}
& \overline{\mathrm{C}}=\frac{\mathrm{C}}{\mathrm{C}_{0}}, \overline{\mathrm{C}}_{s}=\frac{\mathrm{C}_{s}}{\mathrm{C}_{0}}, \overline{\mathrm{C}}_{f s}=\frac{\mathrm{C}_{f s}}{\mathrm{C}_{0}}, \overline{\mathrm{C}}_{f}=\frac{\mathrm{C}_{f}}{\mathrm{C}_{0}}, \overline{\mathrm{C}}_{f w n g}=\frac{\mathrm{C}_{f w r g}}{\mathrm{C}_{0}}, \overline{\mathrm{q}}=\frac{\mathrm{q}}{\mathrm{q}_{0}}, \\
& \overline{\mathrm{L}}_{f}=\frac{\mathrm{L}_{f}}{\mathrm{~L}_{\text {fmax }}} \overline{\mathrm{x}}=\frac{\mathrm{x}}{\mathrm{L}} \overline{\mathrm{z}}=\frac{\mathrm{Z}}{\mathrm{L}_{f}} \overline{\mathrm{r}}=\frac{\mathrm{r}}{\mathrm{R}}
\end{aligned}
$$

Then the system of equations representing the model can be transformed by non-depersonalization as shown below:

$$
\begin{aligned}
& \frac{\partial \overline{\mathrm{C}}(\overline{\mathrm{x}}, \mathrm{T})}{\partial \mathrm{T}}= \mathrm{D}_{d} \frac{\partial^{2} \overline{\mathrm{C}}(\overline{\mathrm{x}}, \mathrm{T})}{\partial \overline{\mathrm{x}}^{2}}-\mathrm{D}_{g} \frac{\partial \overline{\mathrm{C}}(\overline{\mathrm{x}}, \mathrm{T})}{\partial \overline{\mathrm{x}}} \\
&-3 \mathrm{D}_{g} \mathrm{~S}_{f}\left(1+\mathrm{B}_{0} \overline{\mathrm{L}}_{f}\right)^{2}\left[\overline{\mathrm{C}}(\overline{\mathrm{x}}, \mathrm{T})-\overline{\mathrm{C}}_{f s}(\overline{\mathrm{x}}, \mathrm{T})\right] \\
& \frac{\partial \overline{\mathrm{q}}(\overline{\mathrm{r}}, \overline{\mathrm{x}}, \mathrm{T})}{\partial \mathrm{T}}= \frac{\mathrm{E}_{d}}{\mathrm{r}^{2}} \frac{\partial}{\partial \mathrm{r}}\left[\overline{\mathrm{r}}^{2} \frac{\partial \overline{\mathrm{q}}(\overline{\mathrm{r}}, \overline{\mathrm{x}}, \mathrm{T})}{\partial \mathrm{r}}\right] \\
& \frac{\partial}{\partial \mathrm{T}} \int_{0}^{1} \overline{\mathrm{q}}(\overline{\mathrm{r}}, \overline{\mathrm{x}}, \mathrm{T}) \overline{\mathrm{r}}^{2} \overline{\mathrm{dr}}=\mathrm{S}_{t}\left(1+\mathrm{B}_{0} \overline{\mathrm{L}}_{f}\right)^{2}\left[\overline{\mathrm{C}}(\overline{\mathrm{x}}, \mathrm{T})-\overline{\mathrm{C}}_{f s}(\overline{\mathrm{x}}, \mathrm{T})\right] \\
&-\mathrm{A}_{1} \mathrm{D}_{g} \frac{\overline{\mathrm{L}}_{f}(\overline{\mathrm{x}}, \mathrm{T}) \overline{\mathrm{C}}_{f w g}(\overline{\mathrm{x}}, \mathrm{T})}{\mathrm{B}_{1}+\overline{\mathrm{C}}_{f}(\overline{\mathrm{x}}, \mathrm{T})}
\end{aligned}
$$




$$
\begin{aligned}
& \frac{\partial^{2} \overline{\mathrm{C}}_{f}(\overline{\mathrm{x}}, \overline{\mathrm{z}}, \mathrm{T})}{\partial \overline{\mathrm{z}}^{2}}=\mathrm{A}_{2} \frac{\overline{\mathrm{L}}^{2}(\overline{\mathrm{x}}, \mathrm{T}) \overline{\mathrm{C}}_{f}(\overline{\mathrm{x}}, \overline{\mathrm{z}}, \mathrm{T})}{\mathrm{B}_{1}+\mathrm{C}_{f}(\overline{\mathrm{x}}, \overline{\mathrm{z}}, \mathrm{T})} \\
& \frac{\partial^{2} \overline{\mathrm{L}}_{f}(\overline{\mathrm{x}}, \mathrm{T})}{\partial \mathrm{T}}=\mathrm{A}_{3} \mathrm{D}_{g} \frac{\overline{\mathrm{C}}_{f a v g}(\overline{\mathrm{x}}, \mathrm{T}) \overline{\mathrm{L}}_{f}(\overline{\mathrm{x}}, \mathrm{T})}{\mathrm{B}_{1}+\mathrm{C}_{f w g}(\overline{\mathrm{x}}, \mathrm{T})}-\mathrm{A}_{3} \mathrm{D}_{g} \overline{\mathrm{L}}_{f}(\overline{\mathrm{x}}, \mathrm{T}) \\
& \overline{\mathrm{q}}(\overline{\mathrm{r}}=1, \overline{\mathrm{x}}, \mathrm{T})=\overline{\mathrm{C}}_{s}(\overline{\mathrm{x}}, \mathrm{T})^{n}
\end{aligned}
$$

where dimensionless parameters and defined as follows:

$$
\begin{aligned}
& \mathrm{D}=\mathrm{D}_{g} \mathrm{D}_{k} \\
& \mathrm{D}_{g}=\frac{\rho_{a} \mathrm{q}_{o}(1-\varepsilon)}{\varepsilon \mathrm{C}_{o}} \\
& \mathrm{D}_{k}=\frac{\mathrm{D}_{d} \tau}{\mathrm{L}^{2}} \\
& \mathrm{~S}_{t}=\frac{\mathrm{k}_{f c} \tau(1-\varepsilon)}{\mathrm{R} \varepsilon} \\
& \mathrm{B}_{0}=\frac{\mathrm{L}_{\text {fmax }}}{\mathrm{R}} \\
& \mathrm{B}_{1}=\frac{\mathrm{K}_{s}}{\mathrm{C}_{0}} \\
& \mathrm{E}_{d}=\frac{\mathrm{D}_{s} \mathrm{D}_{g} \tau}{\mathrm{R}^{2}} \\
& \mathrm{~A}_{0}=\frac{\mathrm{Q} \tau(1-\varepsilon)}{3 \mathrm{~V}_{0} \varepsilon} \\
& \mathrm{A}_{1}=\frac{\mathrm{k} \tau \mathrm{X}_{f} \mathrm{~L}_{\text {fmax }}}{\mathrm{Yq}_{o} \rho_{a} \mathrm{R}} \\
& \mathrm{A}_{2}=\frac{\mathrm{kX}_{f} \mathrm{~L}_{\text {fmax }}^{2}}{\mathrm{C}_{o} \mathrm{D}_{f}} \\
& \mathrm{~A}_{3}=\mathrm{k} \tau \\
& \mathrm{T}=\frac{\mathrm{t}}{\tau \mathrm{D}_{g}} \\
& \tau=\frac{\mathrm{L}}{\overline{\mathrm{V}}_{x}} \\
& \mathrm{q}_{0}=\mathrm{K}_{F} \mathrm{C}_{0}^{n} \\
& \overline{\mathrm{V}}_{x}=\frac{\mathrm{Q}}{\mathrm{A}}
\end{aligned}
$$

The initial and boundary conditions in dimensionless form are

$$
\begin{aligned}
& \mathrm{C}(\mathrm{x}, \mathrm{T})=0, \mathrm{C}(\mathrm{x}=0, \mathrm{~T})=1,\left.\frac{\partial \overline{\mathrm{C}}(\overline{\mathrm{x}}, \mathrm{T})}{\partial \overline{\mathrm{x}}}\right|_{\bar{x}=1}=0, \overline{\mathrm{q}}(\overline{\mathrm{r}}, \mathrm{T}=0)=0, \\
& \frac{\partial \overline{\mathrm{q}}(\overline{\mathrm{r}}=0, \mathrm{~T})}{\partial \overline{\mathrm{r}}}=0, \overline{\mathrm{C}}_{f}(\overline{\mathrm{x}}, \overline{\mathrm{z}}=0, \mathrm{~T})=\overline{\mathrm{C}}_{s}(\overline{\mathrm{x}}, \mathrm{T}), \overline{\mathrm{L}}_{f}(\overline{\mathrm{x}}, \mathrm{T}=0)=\overline{\mathrm{L}}_{f 0} . \\
& \overline{\mathrm{L}}_{f}\left(\overline{\mathrm{x}}, \mathrm{T}=\mathrm{T}_{\text {max }}\right)=1
\end{aligned}
$$

\section{NUMERICAL SOLUTION}

The numeric calculation was determined from the FORTRAN program by a combined technique of orthogonal collocation and finite difference methods. A number of numerical techniques are available which can be employed to solve these equations. In this study, a combined technique of orthogonal collocation and finite dif- ference methods was employed to obtain long term predictions of effluent concentration profiles for the PSSPC systems. The general philosophy behind application of orthogonal collocation is the reduction of a complicated system of partial differential equations. Orthogonal collocation method was used to solve partial differential Eqs. (7), (8) and (9), and finite difference method, for Eqs. (10), (11). The application of orthogonal collocation to Eq. (7) results in the following ordinary differential equation:

$$
\begin{aligned}
\frac{\mathrm{d} \overline{\mathrm{C}}_{k}}{\mathrm{dT}}= & \mathrm{D} \sum_{j=1}^{M_{c}} \mathrm{BU}_{i j} \overline{\mathrm{C}}_{j}-\mathrm{D}_{g} \sum_{j=1}^{M_{c}} \mathrm{AU}_{i j} \overline{\mathrm{C}}_{j} \\
& -3 \mathrm{D}_{g} \mathrm{~S}_{l}\left(1+\mathrm{B}_{0} \overline{\mathrm{L}}_{f}\right)^{2}\left(\overline{\mathrm{C}}_{k}-\overline{\mathrm{C}}_{f k}\right)\left(\mathrm{k}=2, \mathrm{M}_{C}\right)
\end{aligned}
$$

The subscript $\mathrm{i}$ represents a collocation point in the axial direction and matrices $\mathrm{AU}$ and $\mathrm{BU}$ represent collocation constants for first and second order derivatives determined from the roots of the asymmetric Legendre polynomials as discussed by Finlayson [17]. Application of orthogonal collocation transforms Eq. (11) to the following the ordinary differential equation:

$$
\frac{\mathrm{d} \overline{\mathrm{q}}_{i, k}}{\mathrm{dT}}=\mathrm{E}_{d} \sum_{j=1}^{M_{C}} \mathrm{~B}_{i, j} \overline{\mathrm{q}}_{j, k} \quad\left(\mathrm{i}=1, \mathrm{~N}_{C} ; \mathrm{k}=1, \mathrm{M}_{C}\right)
$$

The subscript counter $\mathrm{i}$ represents a collocation point in the radial direction, and as previously noted, the subscript counter $\mathrm{k}$ represents the axial positions. Adsorbent phase concentrations, $\mathrm{q}_{\mathrm{i}, \mathrm{k}}$ are matrices that represent unknowns resulting from the application of orthogonal collocation in the radial direction on Eq. (29), and the axial direction on Eq. (28). Matrix B represents the set of collocation constants for the Laplacian operator with spherical geometry, and its elements are determined from the roots of symmetric Legendre polynomials as discussed earlier [17]. the application of orthogonal collocation to Eq. (9) results in the following relation involving the adsorbent phase for PSSPC system:

$$
\begin{aligned}
\frac{\mathrm{d} \overline{\mathrm{q}}_{N_{c}, k}=}{\mathrm{dT}}= & {\left[\mathrm{S}_{t}\left(1+\mathrm{B}_{0} \overline{\mathrm{L}}_{j, k}\right)^{2}\left(\overline{\mathrm{C}}_{k}-\overline{\mathrm{C}}_{f s, k}\right)\right.} \\
& \left.-\mathrm{A}_{1} \mathrm{D}_{g} \frac{\overline{\mathrm{L}}_{f, k} \overline{\mathrm{C}}_{f a v g, k}}{\mathrm{~B}_{1}+\overline{\mathrm{C}}_{f a v g, k}}-\sum_{j=1}^{N_{c}-1} \mathrm{~W}_{j} \frac{\left.\mathrm{d} \overline{\mathrm{q}}_{i, k}\right]}{\mathrm{dT}}\right] \frac{1}{\mathrm{~W}_{N_{C}}}
\end{aligned}
$$

The subscript $\mathrm{N}_{C}$ refers to the adsorbent phase concentration at the surface and the subscript $\mathrm{k}$ refers to the axial position. The weighting factors, $\mathrm{W}_{j}$, used for integration, are determined from the roots of symmetric Legendre polynomials [17]. Eq. (30) is valid throughout the bed, or from $\mathrm{k}+1$ to $\mathrm{M}_{C}$. The dimensionless bio-film diffusion equation was solved by using the finite difference method. For diffusion and reaction in the bio-film represented by Eq. (10), the finite difference approximation is

$$
\frac{\overline{\mathrm{C}}_{f, m+1, k}-2 \overline{\mathrm{C}}_{f, m, k}+\overline{\mathrm{C}}_{f, m+1, k}}{\Delta \mathrm{z}^{2}}=\mathrm{A}_{2} \frac{\overline{\mathrm{L}}_{f}^{2} \overline{\mathrm{C}}_{f, m, k}}{\mathrm{~B}_{1}+\overline{\mathrm{C}}_{f, m, k}}
$$

For the growth of bio-film represented by Eq. (11), the relation is

$$
\overline{\mathrm{L}}_{i, j+1, k} \overline{\mathrm{L}}_{i, j, k}\left[1+\Delta \mathrm{T}\left(\frac{\mathrm{A}_{3} \mathrm{D}_{g} \overline{\mathrm{C}}_{\text {favg }, k}}{\mathrm{~B}_{1}+\overline{\mathrm{C}}_{\text {farg }, k}}\right)\right]-\mathrm{A}_{3} \mathrm{D}_{g}
$$

Bio-film thickness is divided into $(\mathrm{m}+1)$ finite points $\overline{\mathrm{C}}_{f, 1, k}$ and $\overline{\mathrm{C}}_{f, m+1, k}$ are calculated from the equations 
Table 1. Physical properties of granular activated carbon (PICABIOL, France)

\begin{tabular}{ll}
\hline \hline Physical properties & Values \\
\hline Apparent density $(\mathrm{g} / \mathrm{cc})$ & $0.24 \mathrm{~min}, 0.30 \mathrm{max}$ \\
Ash content $(\%)$ & $5 \mathrm{max}$ \\
$\mathrm{CCl}_{4}$ adsorption capacity $(\%)$ & $80 \mathrm{~min}$ \\
Iodine number $(\mathrm{mg} / \mathrm{g})$ & $900 \mathrm{~min}$ \\
Moisture content $(\%)$ & $7 \mathrm{max}$ \\
Particle size $(\mathrm{mm})$ & $1.0-1.2$ \\
Specific surface $\left(\mathrm{m}^{2} / \mathrm{g}\right)$ & $1200 \mathrm{~min}$ \\
Uniformity coefficient & $<1.7$ \\
\hline
\end{tabular}

$$
\begin{aligned}
& \overline{\mathrm{C}}_{f, 1, k}=2 \overline{\mathrm{C}}_{s, k}+\frac{\mathrm{A}_{2} \overline{\mathrm{L}}_{j, k}}{\Delta \overline{\mathrm{Z}}^{2}} \frac{\overline{\mathrm{C}}_{s, k}}{\mathrm{~B}_{1}+\overline{\mathrm{C}}_{s, k}} \\
& \overline{\mathrm{C}}_{f, 2, k}=2 \overline{\mathrm{C}}_{f, 1, k}-\overline{\mathrm{C}}_{s, k}+\frac{\mathrm{A}_{2} \overline{\mathrm{L}}_{j, k}}{\Delta \overline{\mathrm{z}}^{2}} \frac{\overline{\mathrm{C}}_{f, 1, k}}{\mathrm{~B}_{1}+\overline{\mathrm{C}}_{f, 1, k}}
\end{aligned}
$$

The number of ordinary differential equations generated by application of orthogonal collocation to axial and radial directions is $\mathrm{M}_{c}-1$ in the liquid phase, and $\mathrm{N}_{c} \times \mathrm{M}_{c}$ in the adsorbent phase, respectively. It was found that seven internal collocation points in the radial direction and eight in the axial direction provided excellent numerical accuracy. Seven ordinary differential equations for the liquid phase, and fifty-six for the adsorbent phase were required, and a total of sixty-three ordinary differential equations were solved by using the algorithm developed by GEAR [18].

\section{CHARACTERISTICS OF DISSOLVED ORGANIC CARBON IN BAC PILOT PLANT}

The activated carbon used in the BAC Pilot Plant has pentagonal or hexagonal structures with long and tubular interior, providing good environmental conditions for the growth of microorganisms. The physical properties of granular activated carbon are presented in Table 1. The surface area and the volume of pores were 2,280 $\mathrm{m}^{2} / \mathrm{g}$ and $1.02 \mathrm{cc} / \mathrm{g}$, respectively. The effective diameter was 1.01 $\mathrm{mm}$, and the uniformity coefficient was 1.297.

The concentrations for the influent ranged 1.2-2.4 $\mathrm{mgC} / \mathrm{L}$ (mean value of $1.76 \mathrm{mgC} / \mathrm{L}$ ) of DOC, $0.4-1.2 \mathrm{mgC} / \mathrm{L}$ (mean value of 0.74 $\mathrm{mgC} / \mathrm{L}$ ) of BDOC, and $0.8-1.2 \mathrm{mgC} / \mathrm{L}$ (mean value of $1.02 \mathrm{mgC} /$ $\mathrm{L}$ ) of NBDOC. The ratios of BDOC/DOC and NBDOC/DOC for the influent of the BAC Pilot Plant ranged from 0.30 to 0.48 (mean value of 0.42 ) and 0.52 to 0.70 (mean value of 0.58 ), respectively. The characteristics of organic carbons for the influent of the BAC Pilot Plant have shown a $42 \%$ biodegradable fraction, and a $58 \%$ non-biodegradable fraction. The characteristics of the organic carbons for the effluent in the BAC Pilot Plant have shown a $45 \%$ nonremoved fraction, a $31 \%$ biodegradable fraction, and a $24 \%$ adsorbed fraction. The properties and removal mechanisms of the organic carbons in the BAC Pilot Plant are presented in Fig. 2.

\section{BREAKTHROUGH BEHAVIORS OF ORGANIC CARBONS IN BAC PILOT PLANT}

The breakthrough behaviors of organic carbons in the BAC Pilot

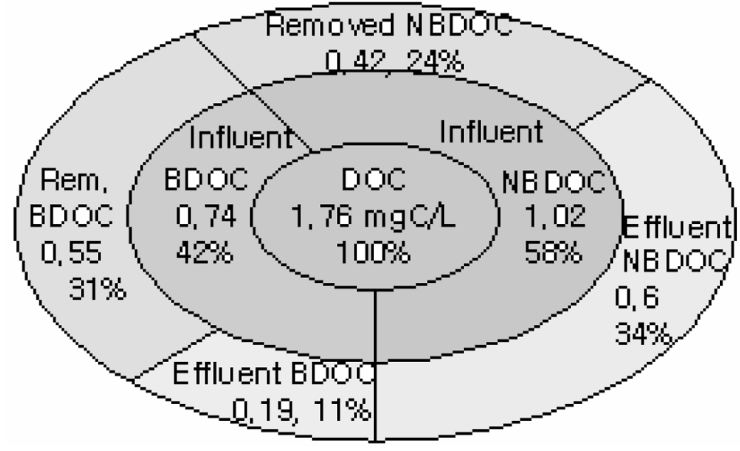

Fig. 2. Properties and removal mechanisms of organic carbons in BAC pilot plant.

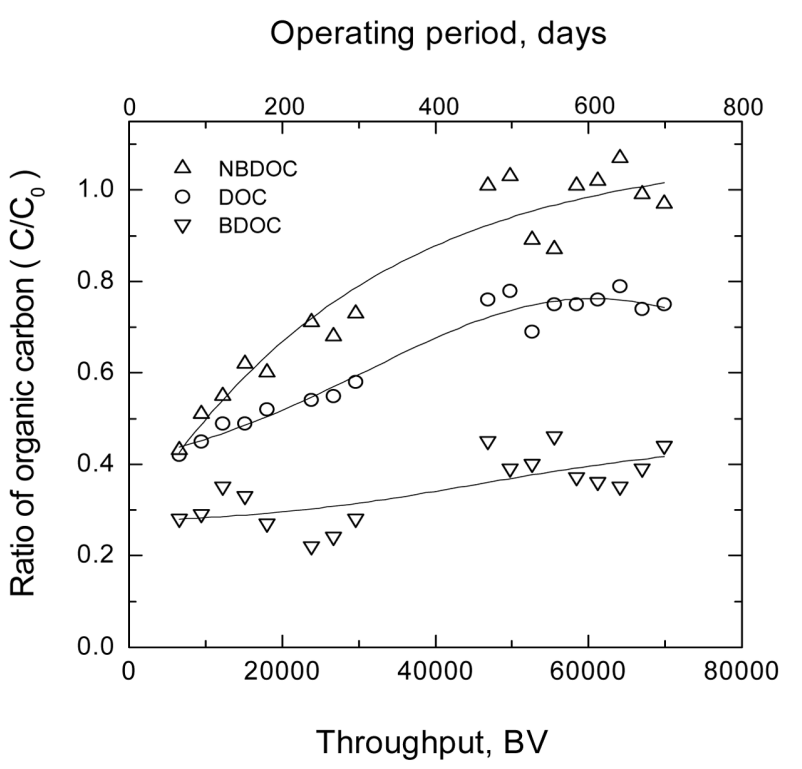

Fig. 3. Breakthrough behaviors of organic carbons in BAC pilot plant.

Plant are presented in Fig. 3. The breakthrough profile of dissolved organic carbon measured under the bed volume of 10,000 was 0.425 . The $\mathrm{DOC} / \mathrm{DOC}_{0}$ ratio measured under the maximum bed volume of 70,000 was 0.7 , so it was observed that the $\mathrm{BAC}$ process retained the removal performance.

The mineral content measured under the maximum bed volume of 70,000 is presented in Table 2. The activated carbon contained the iron and aluminum accumulated from the coagulant used, the calcium, magnesium and manganese accumulated from the surface water, and small traces of harmful heavy metals (lead, cadmium and chromium). Specifically, carbon dioxide (bicarbonate, carbonate), a decomposition by-product of organic carbon, was combined with calcium to produce and accumulate as a form of calcium carbonate.

\section{PREDICTION OF DISSOLVED ORGANIC CARBON FOR EFFLUENT IN BAC PILOT PLANT BY THE PSSPC MODEL}

The concentrations of organic carbon were estimated for a two- 
Table 2. Mineral content measured under the maximum bed volume in BAC pilot plant

\begin{tabular}{|c|c|c|c|c|c|c|c|}
\hline \begin{tabular}{|l|l|} 
Mineral & EBCT \\
\end{tabular} & $0 \mathrm{~min}$ & $5 \mathrm{~min}$ & $15 \mathrm{~min}$ & Mineral & $0 \mathrm{~min}$ & $5 \mathrm{~min}$ & $15 \mathrm{~min}$ \\
\hline $\mathrm{K}(\mathrm{ppm})$ & 2,528 & 840 & 736 & $\mathrm{~K}(\mathrm{ppm})$ & 2,528 & 840 & 736 \\
\hline $\mathrm{Na}(\mathrm{ppm})$ & 386 & 462 & 500 & $\mathrm{Na}(\mathrm{ppm})$ & 386 & 462 & 500 \\
\hline $\mathrm{Pb}(\mathrm{ppm})$ & 3 & 10 & 8 & $\mathrm{~Pb}(\mathrm{ppm})$ & 3 & 10 & 8 \\
\hline $\mathrm{Cd}(\mathrm{ppm})$ & 6 & 20 & 20 & $\mathrm{Cd}(\mathrm{ppm})$ & 6 & 20 & 20 \\
\hline $\mathrm{Cu}(\mathrm{ppm})$ & 323 & 1,063 & 565 & $\mathrm{Cu}(\mathrm{ppm})$ & 323 & 1,063 & 565 \\
\hline $\mathrm{Cr}(\mathrm{ppm})$ & 32 & 116 & 30 & $\mathrm{Cr}(\mathrm{ppm})$ & 32 & 116 & 30 \\
\hline
\end{tabular}

Table 3. Input parameters for plug-flow stationary solid phase column model in BAC pilot plant

\begin{tabular}{|c|c|c|c|c|c|}
\hline Parameters & Model units & Values & Parameters & Model units & Values \\
\hline $\mathrm{D}_{S}\left(\mathrm{~cm}^{2} / \mathrm{sec}\right)$ & DS & $3.63 \times 10^{-9}$ & $\mathrm{Q}(\mathrm{ml} / \mathrm{min})$ & FLRT & 25,000 \\
\hline $\mathrm{R}(\mathrm{cm})$ & RAD & 0.06 & . & DH0 & $0.11 \times 10^{-3}$ \\
\hline $\mathrm{k}_{f c}(\mathrm{~cm} / \mathrm{sec})$ & XKF & $1.81 \times 10^{-3}$ & . & TDTOL & $0.10 \times 10^{7}$ \\
\hline $\mathrm{C}_{0}(\mathrm{mg} / \mathrm{l})$ & CB0 & 1.58 & . & DTOUT & $0.11 \times 10^{-1}$ \\
\hline . & EPS & $0.5 \times 10^{-3}$ & W (g) & WT & $58,810.6$ \\
\hline $\mathrm{K}_{F}$ & XK & 2.12 & DIA $(\mathrm{cm})$ & DIA & 40.0 \\
\hline $\mathrm{n}$ & $\mathrm{XN}$ & 1.11 & $\rho_{a}\left(\mathrm{~g} / \mathrm{cm}^{3}\right)$ & RHOP & 0.24 \\
\hline$\cdot$ & DSTEP & $0.2 \times 10^{2}$ & $\mathrm{k}\left(\min ^{-1}\right)$ & BK & 0.02 \\
\hline $\mathrm{L}(\mathrm{cm})$ & XL & 300.0 & $\mathrm{Y}(\mathrm{mg} / \mathrm{mg})$ & YY & 0.125 \\
\hline$\cdot$ & NSTEP & 500 & $\mathrm{~K}_{S}(\mathrm{mg} / \mathrm{l})$ & BKS & 6.5 \\
\hline . & $\mathrm{NC}$ & 7 & $\mathrm{k}_{d}\left(\min ^{-1}\right)$ & BKD & $1.33 \times 10^{-3}$ \\
\hline . & $\mathrm{MC}$ & 8 & $\mathrm{X}_{f}\left(\mathrm{mg} / \mathrm{cm}^{3}\right)$ & $\mathrm{XF}$ & 0.78 \\
\hline . & MF & 22 & $\mathrm{~L}_{f 0}(\mathrm{~cm})$ & BLF0 & $0.11 \times 10^{-4}$ \\
\hline . & NCOL & 0 & $\mathrm{~L}_{\text {fmax }}(\mathrm{cm})$ & BLFM & $1.0 \times 10^{-4}$ \\
\hline . & JIN & 0 & $\mathrm{D}_{f}\left(\mathrm{~cm}^{2} / \mathrm{sec}\right)$ & $\mathrm{DF}$ & $1 \times 10^{-6}$ \\
\hline . & NM & 2 & $\cdot$ & DELZ & 1.0 \\
\hline . & NDATA & 24 & & & \\
\hline
\end{tabular}

year operation in the BAC Pilot Plant by using the plug flow stationary solid phase column model. The input parameters for the PSSPC model are presented in Table 3. The values of $\mathrm{K}_{F}$ and $n$ are 2.12 and 1.11 when measured by Freundlich adsorption isotherm experiment. The mass transport parameters, $\mathrm{k}_{f c}$, and intra particle surface diffusion coefficient, $\mathrm{D}_{s}$, estimated from the referenced article $[12,16]$, are $1.81 \times 10^{-3} \mathrm{~cm} / \mathrm{sec}$ and $3.63 \times 10^{-9} \mathrm{~cm} / \mathrm{sec}$. The values of Monod kinetic constants characterized by $\mathrm{k}, \mathrm{K}_{s}, \mathrm{Y}$, and $\mathrm{k}_{d}$ are $0.02 / \mathrm{min}, 6.5$ $\mathrm{mg} / \mathrm{L}, 0.125,1.33 \times 10^{-3} / \mathrm{min}$, respectively. The values of biomass density in biofilm, $\mathrm{X}_{f}$, and biofilm diffusion coefficient, $\mathrm{D}_{f}$, are 0.78 $\mathrm{mg} / \mathrm{cm}^{3}, 1 \times 10^{-6} \mathrm{~cm}^{2} / \mathrm{sec}$, respectively.

The breakthrough profiles of dissolved organic carbon by the PSSPC model are shown in Fig. 4. The predicted breakthrough profiles of dissolved organic carbon maintained a certain value of 0.450 according to the bed volume. The breakthrough profile of dissolved organic carbon measured under the bed volume of 10,000 was 0.425 . We found that the plug-flow stationary solid phase column model provided good accuracy for prediction of breakthrough profiles in the BAC Pilot Plant.

\section{SENSITIVITY OF THE PSSPC MODEL FOR GAC COLUMN}

The pores of the granular activated carbon are accumulated with
Operating period, days

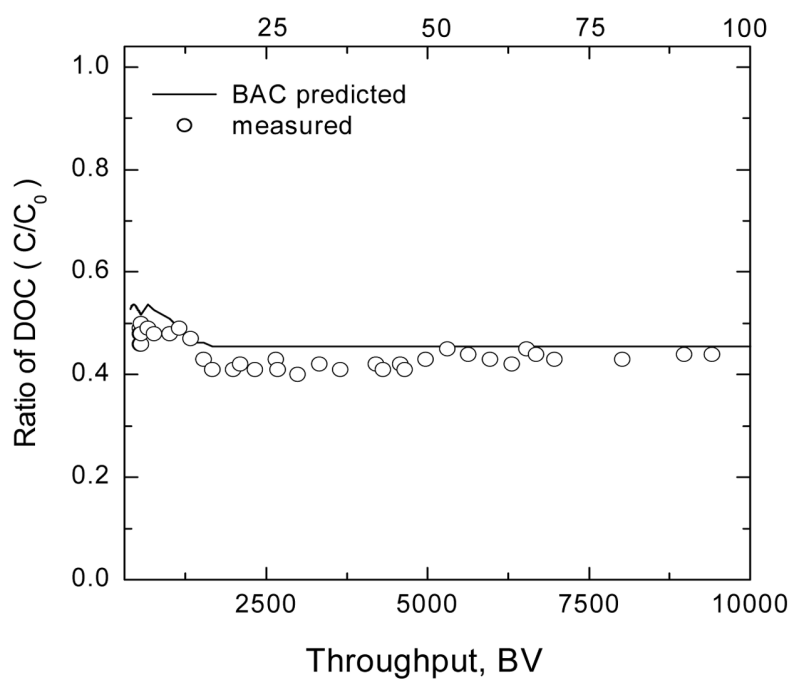

Fig. 4. Breakthrough profiles of dissolved organic carbon by the PSSPC model.

organic matter, and the growth of microorganism increases actively, resulting in an increase in biomass density. However, if the pores 
Table 4. Input parameters for model sensitivity in granular activated carbon column

\begin{tabular}{lclclc}
\hline \hline Parameters & Values & Parameters & Values & Parameters & Values \\
\hline $\mathrm{Q}(\mathrm{ml} / \mathrm{min})$ & 10 & $\rho_{a}\left(\mathrm{~g} / \mathrm{cm}^{3}\right)$ & 0.38 & $\mathrm{~L}_{f 0}(\mu \mathrm{m})$ & 0.11 \\
$\mathrm{C}_{0}(\mathrm{mg} / l)$ & 2.4 & $\mathrm{~K}_{F}(-)$ & 2.12 & $\mathrm{~L}_{\text {fnax }}(\mu \mathrm{m})$ & 2.3 \\
$\mathrm{DIA}(\mathrm{cm})$ & 2 & $\mathrm{n}(-)$ & 1.11 & $\mathrm{~K}_{S}(\mathrm{mg} / l)$ & 5.0 \\
$\mathrm{~L}(\mathrm{~cm})$ & 5 & $\mathrm{D}_{f}\left(\mathrm{~cm}^{2} / \mathrm{sec}\right)$ & $1 \times 10^{-6}$ & $\mathrm{Y}(\mathrm{mg} / \mathrm{mg})$ & 0.1 \\
$\mathrm{R}(\mathrm{cm})$ & 0.06 & $\mathrm{k}_{\left(\mathrm{min}^{-1}\right)}$ & 0.02 & $\mathrm{D}_{s}(\mathrm{~cm} / \mathrm{sec})$ & $3.63 \times 10^{-9}$ \\
$\mathrm{~W}(\mathrm{~g})$ & 4 & $\mathrm{k}_{d}\left(\mathrm{~min}^{-1}\right)$ & $1.33 \times 10^{-3}$ & $\mathrm{k}_{f c}(\mathrm{~cm} / \mathrm{sec})$ & $1.81 \times 10^{-3}$ \\
\hline
\end{tabular}

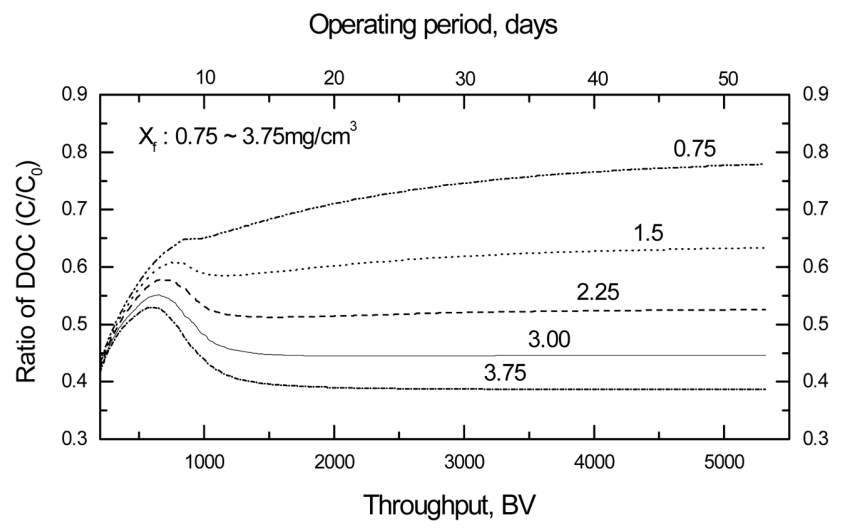

Fig. 5. Breakthrough profiles depicting effects of biomass density in bio-film.

are filled with inorganic matter and metals, the available space for microorganism decreases, which also decreases the biomass density.

The input parameters for sensitivity analysis in the PSSPC model are presented in Table 4. Effects of biomass density on breakthrough profiles for the PSSPC model are illustrated in Fig. 5. The biomass density ranged from $2.25-3.75 \mathrm{mg} / \mathrm{cm}^{3}$, with the breakthrough profiles maintaining the steady-state. When the biomass density ranged from $0.75-1.5 \mathrm{mg} / \mathrm{m}^{3}$, the DOC breakthrough curves continued to be saturated as the bed volume increased. Therefore, it is necessary to retain the biomass density if we are to maintain the performance in the BAC Pilot Plant for long-term periods.

\section{CONCLUSIONS}

The following conclusions are reached on the basis of the results of this research.

The characteristics of the organic carbons for the effluent in the biological activated carbon pilot plant have shown a $45 \%$ non-removed fraction, a $31 \%$ bio-degraded fraction, and a $24 \%$ adsorbed fraction. The breakthrough profile of dissolved organic carbon measured under the bed volume of 10,000 was 0.425 .

The input parameters for the plug-flow stationary solid phase column model in the biological activated carbon pilot plant are shown below. The values of $\mathrm{K}_{F}$ and $\mathrm{n}$ are 2.12 and 1.11 when measured by Freundlich adsorption isotherm experiment. The values of $\mathrm{k}_{f c}$ and $\mathrm{D}_{s}$ estimated from the referenced article are $1.81 \times 10^{-3} \mathrm{~cm} / \mathrm{sec}$ and $3.63 \times 10^{-9} \mathrm{~cm} / \mathrm{sec}$. The Monod kinetic constants characterized by $\mathrm{k}, \mathrm{K}_{s}, \mathrm{Y}$, and $\mathrm{k}_{d}$ are $0.02 / \mathrm{min}, 6.5 \mathrm{mg} / \mathrm{L}, 0.125,1.33 \times 10^{-3} / \mathrm{min}$, respectively. The biomass density in biofilm, $\mathrm{X}_{f}$, and biofilm diffusion coefficient, $\mathrm{D}_{f}$, are $0.78 \mathrm{mg} / \mathrm{cm}^{3}, 1 \times 10^{-6} \mathrm{~cm}^{2} / \mathrm{sec}$, respectively.
The predicted breakthrough profiles of dissolved organic carbon maintained a certain value of 0.450 according to the bed volume. Therefore, the plug-flow stationary solid phase column model provided a good accuracy for prediction of breakthrough profiles in the biological activated carbon pilot plant.

\section{NOMENCLATURE}

A : cross section area $\left[\mathrm{L}^{2}\right]$

$\mathrm{A}_{p} \quad$ : total surface area available for mass transfer $\left[\mathrm{L}^{2}\right]$

a : surface area per particle $\left[\mathrm{L}^{2}\right]$

AU : unsymmetric second order collocation constant

B : symmetric second order collocation constant

BAC : biological activated carbon [-]

BDOC : biodegradable dissolved organic carbon [mg C/L]

BU : unsymmetric first order collocation constant

BV : bed volume [-]

C : substrate concentration in liquid phase $\left[\mathrm{M}_{s} / \mathrm{L}^{3}\right]$

$\mathrm{C}_{f}$ : substrate concentration in biofilm $\left[\mathrm{M}_{s} / \mathrm{L}^{3}\right]$

$\mathrm{C}_{\text {favg }}$ : average substrate concentration in biofilm $\left[\mathrm{M}_{s} / \mathrm{L}^{3}\right]$

$\mathrm{C}_{f s} \quad$ : substrate concentration at biofilm/liquid interface $\left[\mathrm{M}_{s} / \mathrm{L}^{3}\right]$

$\mathrm{C}_{0} \quad$ : influent substrate concentration $\left[\mathrm{M}_{s} / \mathrm{L}^{3}\right]$

$\mathrm{C}_{s}$ : substrate concentration near activated carbon surface $\left[\mathrm{M}_{s} /\right.$ $\left.\mathrm{L}^{3}\right]$

$\mathrm{D}_{f} \quad$ : substrate diffusion coefficient in biofilm $\left[\mathrm{L}^{2} / \mathrm{T}\right]$

$\mathrm{D}_{s}$ : substrate diffusion coefficient in activated carbon $\left[\mathrm{L}^{2} / \mathrm{T}\right]$

DH0 : dimensional H0

DIA : diameter of the activated carbon column [L]

DOC : dissolved organic carbon [mg C/L]

DSTEP : dimensional TSTEP [T]

DTOUT : dimensional TOUT [T]

EPS : relative error criteria

GAC : granular activated carbon [-]

JIN : total number of varying influent concentration value

$\mathrm{k} \quad$ : maximum specific substrate utilization rate $\left[\mathrm{M}_{s} / \mathrm{M}_{x} \mathrm{~T}\right]$

$\mathrm{k}_{d} \quad$ : overall biofilm loss coefficient $\left[\mathrm{T}^{-1}\right]$

$\mathrm{k}_{f c} \quad$ : liquid film transfer coefficient in column study [L/T]

$\mathrm{K}_{F} \quad$ : Freundlich isotherm constant $\left[\mathrm{M}_{s} / \mathrm{M}_{q}\right]\left[\mathrm{L}^{3} / \mathrm{M}_{s}^{n}\right]$

$\mathrm{K}_{s} \quad$ : monod half saturation coefficient $\left[\mathrm{M}_{s} / \mathrm{L}^{3}\right]$

$\mathrm{L}_{f} \quad$ : biofilm thickness [L]

$\mathrm{L}_{f 0} \quad$ : initial biofilm thickness [L]

$\mathrm{L}_{\text {fmax }}$ : maximum biofilm thickness [L]

$\mathrm{m}$ : number of finite points in the biofilm

$\mathrm{M}_{c}$ : number of internal collocation points in the axial direction

MF : integration method

n : Freundlich isotherm constant

$\mathrm{N}_{c}$ : number of internal collocation points in the radial direction 
NBDOC : non-biodegradable dissolved organic carbon [mg C/L]

NCOL : if $=1$, print coll. consts. if $=0$, don't

NDATA : number of experimental data points

NM : size of vectors tinc and tie

NSTEP : maximum number of colls to GEAR

PSSPC : plug-flow stationary solid phase column

$\mathrm{q}$ : sorbed phase substrate concentration $\left[\mathrm{M}_{s} / \mathrm{M}_{q}\right]$

Q : influent flowrate $\left[\mathrm{L}^{3} / \mathrm{T}\right]$

$\mathrm{r} \quad$ : radial coordinate in activated carbon particle [L]

$\mathrm{R}$ : radius of activated carbon particle [L]

$\mathrm{t}:$ : time [T]

$\mathrm{t}_{\max }$ : time corresponding to maximum film thickness [T]

$\mathrm{t}_{0} \quad$ : initial time [T]

$\mathrm{T}_{\max }$ : dimensionless time corresponding to $\mathrm{t}_{\max }$

$\Delta \mathrm{T}:$ dimensionless increment for time

TDTOL : total time of run [T]

$\mathrm{V}_{x} \quad$ : interstitial axial fluid velocity [L/T]

$\mathrm{W}$ : weighting factor for collocation integration of the symmetric Legendre polynomials

WT : weight of activated carbon in adsorber $\left[\mathrm{M}_{q}\right]$

$\mathrm{x}$ : coordinate for axial position in activated carbon bed [L]

$\mathrm{X}_{f} \quad$ : biomass density in biofilm $\left[\mathrm{M}_{x} / \mathrm{L}^{3}\right]$

$\mathrm{Y}$ : microbial yield coefficient $\left[\mathrm{M}_{x} / \mathrm{M}_{s}\right]$

$\mathrm{Z} \quad$ : coordinate for position in biofilm [L]

$\Delta \mathrm{z} \quad$ : dimensionless increment for position $\mathrm{z}$ in biofilm

\section{Greek Letters}

$\rho_{a} \quad:$ apparent density of activated carbon $\left[\mathrm{M}_{q} / \mathrm{L}^{3}\right]$

$\varepsilon \quad$ : fraction of volumetric space unoccupied by activated carbon

$\tau \quad$ : empty bed contact time [T]

\section{REFERENCES}

1. C. Hubele, Adsorption und biologischer abbau von huminstoffen in aktivkohlefiltern, Diss. Univ. Karlsruhe (1985).

2. W. Ying and W. J. Weber, $W P C F, \mathbf{5 1}, 2661$ (1979).

3. P. A. Jennings, Ph.D., Dissertation, University of Illinois, Urbana Champaign (1975).

4. R. Peel and A. Benedek, AIChE Sym. Ser., 73, 25 (1975).

5. F. A. Digiano, K. Dovantzis and G E. Speitel, Proc. National Conf. on Environ. Eng., ASCE, 382 (1984).

6. H. T. Chang and B. E. Rittmann, Environ. Sci. Tech., 21, 280 (1987).

7. J. E. Lee and J. K. Lee, Korean J. Chem. Eng., 19, 703 (2002).

8. J. E. Lee, W. S. Choi and J. K. Lee, Korean J. Chem. Eng., 20, 943 (2003).

9. J. A. Rhim and J. H. Yoon, Korean J. Chem. Eng., 22, 201 (2005).

10. D. Y. Kim, S. B. Lee and J. A. Rhim, KSEE, 15, 717(1993).

11. J. A. Rhim, Korean J. Chem. Eng., 23, 38 (2006).

12. J. A. Rhim, J. H. Yoon and D. Y. Kim, KSEE, 19, 1455 (1997).

13. J. C. Joret and Y. Levi, Method rapide d'evaluation du carbone eliminable des eaux par voie biologique, Trib. Cebedeau (1986).

14. D.Y. Kim, J. A. Rhim, J. H. Yoon and S. B. Lee, Water Supply, 14, 285 (1996).

15. J. A. Rhim, J. H. Yoon, S. H. Kim and D. Y. Kim, KSEE, 21, 27 (1999).

16. S. H. Kim and B. M. Min, Korean J. Chemical Eng., 10, 18 (1993).

17. B. A. Finlayson, The method of weighted residuals and variational principles, Academic Press, New York (1972).

18. C. W. Gear, Numerical initial value problems in ordinary differential equations, Prentice Hall, Englewood Cliff, N. J. (1976). 